\title{
Study on the Relationship between Stromal Cell-Derived Factor-1 (SDF-1) and Gastric Cancer
}

\author{
Xiulian $\mathrm{Xu}^{1,2}$ (), Yurong Song1,2, Shoujiang Wei ${ }^{1,2}$, Chongshu Wang1,2* \\ ${ }^{1}$ The First Department of General Surgery, Affiliated Hospital of North Sichuan Medical College, Nanchong, China \\ ${ }^{2}$ Courage Pancreatic Bowel Disease Institute, Affiliated Hospital of North Sichuan Medical College, Nanchong, China \\ Email: *chongs-wang@163.Com
}

How to cite this paper: Xu, X.L., Song, Y.R., Wei, S.J. and Wang, C.S. (2019) Study on the Relationship between Stromal CellDerived Factor-1 (SDF-1) and Gastric Cancer. Health, 11, 332-340. https://doi.org/10.4236/health.2019.113029

Received: January 20, 2019

Accepted: March 11, 2019

Published: March 14, 2019

Copyright $\odot 2019$ by author(s) and Scientific Research Publishing Inc. This work is licensed under the Creative Commons Attribution International License (CC BY 4.0).

http://creativecommons.org/licenses/by/4.0/

\section{(c) () Open Access}

\begin{abstract}
Whether SDF-1 is related to the occurrence and development of gastric cancer, we collected gastric cancer tissues and corresponding non-cancerous gastric tissues from 52 patients with gastric cancer, and detected the expression of SDF-1 by real-time fluorescence quantitative polymerase chain reaction (RT-PCR) and immunohistochemistry. We also analyzed the relationship between the expression level and clinicopathological characteristics. In both cases SDF-1 gene and protein expression in gastric cancer tissues were significantly higher than in corresponding non-cancerous gastric tissues (both $\mathrm{P}<$ 0.01 ), but no significant relationship was found with clinicopathological parameters including tumor location, depth of invasion, differentiation, lymphnode metastasis, stage, gender, age and carcinoembryonic antigen (CEA), and carbohydrate antigen 19-9 (CA19-9) level in peripheral blood preoperation of patients $(\mathrm{P}>0.05$, respectively). Also, there were no significant relations hip in gastric cancer tissues of Helicobacter pylori (HP)-positive patients and negative ones $(\mathrm{P}>0.05)$. The result of the study showed that SDF-1 might play a significant role in the process of formation and development of gastric cancer as an oncogene, but could not be used as an index to judge prognosis and predict recurrence.
\end{abstract}

\section{Keywords}

SDF-1, Clinicopathological Characteristics, Gastric Cancer, HP

\section{Introduction}

Gastric cancer is one of the most common malignancies in humans. More than 900,000 newly diagnosed cases and approximately 700,000 gastric cancer pa- 
tients die each year worldwide [1]. In China, its morbidity and mortality account for the first of all digestive system malignancies. It is of great significance to study the occurrence and development of gastric cancer from the level of gene to improve the therapeutic effect of gastric cancer. Stromal cell-derived factor-1 (SDF-1, also known as CXCL12) is a member of the CXC chemokine family that binds to the receptor CXCR4 and participates in the body's hematopoiesis, stem cell production, leukocyte infiltration, nerves, vascular and cardiac formation and HIV infection and a series of physiological and pathological processes. In recent years, studies have found that SDF-1 is associated with tumorigenesis, infiltration, and metastasis [2] [3] [4]. In this study, real-time fluorescence quantitative reverse transcription polymerase chain reaction (RT-PCR) and immunohistochemistry were used to detect the expression of SDF-1 in gastric cancer tissues. The correlation between SDF-1 and related clinicopathological parameters was investigated. The relationship among proliferation, invasion, and metastasis of gastric cancer determines whether the SDF-1 gene can serve as an indicator of prognosis and predictive recurrence will be explained in this study.

\section{Materials and Methods}

\subsection{Patient Characteristics}

After inform consent forms were signed, the specimens including gastric cancer and corresponding noncancerous gastric tissues in general surgery of affiliated hospital of North Sichuan Medical College during April to July in 2016 were collected. All cases were diagnosed as gastric adenocarcinoma with pathologicalbiopsy both preoperation and postoperation. They who had taken anti-HP drug or chemotherapy or radiotherapy lately were removed. The clinicopathological characteristics of patients are summarized in Table 1.

\subsection{Samples}

All samples consisted of gastric cancer and corresponding non-cancerous gastric tissues were obtained intraoperation just after they were cut off. Then part was put into $-80^{\circ} \mathrm{C}$ refrigerator quickly used for total RNA extraction. The left was dipped in formalin and then embedded with paraffins for INH.

\subsection{Detection of HP}

14C-urea breath test simple, fast and inexpensive, sensitivity greater than 95\%, specificity greater than 90\%, HP infection for the first-line diagnosis [8]. Patients were arranged to take 14C-urea breath test to detect HP value preoperation. They whose HP values lower than $100 \mathrm{dpm}$ were regarded as negative, and the others positive. Due to cardia complete obstruction or poor compliance, $11 \mathrm{pa}-$ tients did not accept 14C-urea breath test.

\subsection{RT-PCR}

104 gastric cancer and corresponding non-cancerous gastric tissues were ground 
Table 1. Patient clinicopathological characteristics.

\begin{tabular}{|c|c|}
\hline Characteristic & $\mathrm{N}=52$ \\
\hline \multirow[t]{2}{*}{ Gender } & Male 41 \\
\hline & Female 11 \\
\hline \multirow[t]{2}{*}{ Age (years) } & Mean $58.6 \pm 11.7$ \\
\hline & Range 31 - 79 \\
\hline \multirow[t]{3}{*}{ Differentiation } & Well 2 \\
\hline & Moderate 14 \\
\hline & Poor 36 \\
\hline \multirow[t]{3}{*}{ Location of tumor } & Upper 13 \\
\hline & Middle 14 \\
\hline & Lower 25 \\
\hline \multirow[t]{4}{*}{ Depth of invasion [5] } & T1 10 \\
\hline & T2 10 \\
\hline & T3 0 \\
\hline & T4 32 \\
\hline \multirow[t]{4}{*}{ Lymph node metastasis [6] } & N0 20 \\
\hline & N1 10 \\
\hline & N2 14 \\
\hline & N3 8 \\
\hline \multirow[t]{4}{*}{ Stage $[7]$} & I 15 \\
\hline & II 10 \\
\hline & III 24 \\
\hline & VI 3 \\
\hline
\end{tabular}

into fine powder with mortars and pestles in liquid nitrogen. Then total RNA was extracted with TRizol Reagent (Tiangen, China). Later the quality of total RNA was assessed with ultraviolet spectrophotometer (SHIMADZU, Japan) andagarose gel electrophoresis (agarose from Sigma, America; electrophoresis apparatus from BIO-RAD, America). cDNA was synthesized using reverse transcription kit (BioBRK, China) according to instruction. RT-PCR thermocycler (ABI, America) and kit (Takara, Japan) including Pre Mix, Dye and DNase/RNase free ddH2O were used for cDNA amplification. $1 \mu \mathrm{l}$ cDNA, $10 \mu \mathrm{l}$ Pre Mix, $2 \mu \mathrm{l}$ Dye, forward and reverse primer both $0.6 \mu \mathrm{l}(10 \mathrm{pmol} / \mu \mathrm{l})$ and $5.8 \mu \mathrm{l}$ DNase/RNase free $\mathrm{ddH} 2 \mathrm{O}$ were consisted in amplification system. And $\beta$-actin primers were synthesized by Invitrogen Company. The primer sequence, reaction condition and product size are all in Table 2. All samples were tested duplicately. After amplification finished, dissociation curve was analyzed to identify the uniqueness of product. $2-\Delta \mathrm{CT}$ was used as relative expression value.

\subsection{INH}

Paraffins embedded 104 gastric cancer and corresponding non-cancerous gastric tissues were sectioned to $3 \mu \mathrm{m}$ in thickness. After the slices were dipped in dimethyl benzene twice each for $10 \mathrm{~min}$, they were put into $100 \%$ alcohol, $85 \%$ alcohol and 75\% alcohol successively, and then washed with running water for deparaffinization. $3 \% \mathrm{H}_{2} \mathrm{O}_{2}$ covered the whole tissues on slices for $20 \mathrm{~min}$ at 
Table 2. Primer sequence, reaction condition and product size.

\begin{tabular}{cccc}
\hline Primer name & Primer sequence & Product size (bp) & Reaction condition \\
\hline SDF-1 & ATTCTCAACACTCCAAACTGTGC & 88 & $\$ 5^{\circ} \mathrm{C} 30 \mathrm{sec} 1 \mathrm{cycle}$ \\
& ACTTTAGCTTCGGGTCAATGC & & $\$ 5^{\circ} \mathrm{C} 3 \mathrm{sec}$ \\
$\beta$-actin & GAGCTACGAGCTGCCTGAC & 120 & $60^{\circ} \mathrm{C} 30 \mathrm{sec} 40 \mathrm{cycle}$ \\
& GTAGTTTCGTGGATGCCAC & &
\end{tabular}

room temperature and away from light in order to block endogenous peroxidase activity. Heat antigen retrieval was performed in $0.01 \mathrm{M}$ citrate buffer (ph6.0) at $95^{\circ} \mathrm{C}$ for $20 \mathrm{~min}$. Then slices were incubated with Rabbit anti SDF-1 monoclonal antibody (ABCAM, England) at a dilution of 1:150 (final concentration: 6.67 $\mu \mathrm{g} / \mathrm{ml})$ at $4^{\circ} \mathrm{C}$ overnight. At the next morning the slices were incubated with common secondary antibody (ABCAM, England) at room temperature for 15 min. After colorated with diaminobenzidine and counterstained with hematoxylin, the reaction products were visible. All slices were assessed by two professors of pathology who had no knowledge of any clinic pathological characteristics of the patients. Immunohistochemical results were evaluated for intensity and staining frequency of nuclear and cytoplasmic components. The intensity of staining was graded 0 (negative), 1 (weak), 2 (moderate), and 3 (strong). The frequency was graded from 0 to 5 according to the percentage of positive cells as follows: 0 ) there was no cell stained; 1$) \leq 1 \%$; 2) $2 \%$ to $\leq 10 \%$; 3 ) $11 \%$ to $50 \%$; 4 ) $51 \%$ to $80 \%$; 5 ) $\geq 80 \%$. Two scores were $\geq 1$ points judged as positive for SDF-1 expression [9].

\subsection{Statistical Analysis}

T-test or One-way analysis of variance was used for PCR data statistics, and Chi-square test was used for INH results. $\mathrm{P}<0.05$ was considered to have statistical significance.

\section{Results}

\subsection{Expression of Gene by RT-PCR}

\subsubsection{Expression of SDF-1 Gene in Gastric Cancer and Corresponding Non-Cancerous Gastric Tissues}

The mean $\triangle \mathrm{CT}$ value of SDF-1 in gastric cancer and corresponding non-cancerous gastric tissues were $5.24 \pm 1.23 ; 10.98 \pm 1.35(\mathrm{t}=-23.33, \mathrm{P}<0.01)$ (Figure 1$)$.

\subsubsection{Relationship between SDF-1 Gene Expression and Clinicopathological Characteristics of Gastric Cancer Patient}

The CEA data of 3 patients and CA19-9 of 2 patients were lost, so they were removed when made those two statistics analysis. No significant relationship was found between SDF-1 and clinic pathological characteristics, including gender, age, tumor's location, depth of invasion, differentiation, lymph node metastasis, stage and CEA, CA19-9 level in peripheral blood reoperation (Table 3). 
Table 3. The expression of SDF-1 gene in gastric cancer tissues in different clinicopathological characteristics.

\begin{tabular}{|c|c|c|c|c|}
\hline Characteristics & $\mathrm{N}$ & Expression of SDF-1gene & $\mathrm{T} / \mathrm{F}$ & $\mathrm{P}$ \\
\hline \multicolumn{5}{|l|}{ Gender } \\
\hline Male & 41 & $6.01 \pm 1.37$ & -0.353 & 0.729 \\
\hline Female & 11 & $5.83 \pm 1.53$ & & \\
\hline \multicolumn{5}{|l|}{ Age } \\
\hline $0-50$ & 15 & $5.85 \pm 1.04$ & & \\
\hline $50-60$ & 12 & $5.59 \pm 1.36$ & 1.160 & 0.335 \\
\hline $60-70$ & 15 & $5.93 \pm 1.48$ & & \\
\hline$\geq 70$ & 10 & $6.66 \pm 1.71$ & & \\
\hline \multicolumn{5}{|l|}{ Stage } \\
\hline I & 15 & $5.18 \pm 0.78$ & & \\
\hline II & 8 & $5.37 \pm 1.97$ & 0.236 & 0.871 \\
\hline III & 19 & $5.44 \pm 0.69$ & & \\
\hline IV & 7 & $5.04 \pm 1.88$ & & \\
\hline \multicolumn{5}{|c|}{ Lymph node metastasis } \\
\hline No & 20 & $5.19 \pm 1.39$ & & \\
\hline N1 & 10 & $5.44 \pm 0.99$ & 0.287 & 0.834 \\
\hline $\mathrm{N} 2$ & 14 & $5.47 \pm 0.76$ & & \\
\hline N3 & 8 & $5.04 \pm 1.88$ & & \\
\hline \multicolumn{5}{|l|}{ Differentiation } \\
\hline Poor & 36 & $5.25 \pm 1.37$ & 0.374 & 0.710 \\
\hline Moderate - Well & 16 & $5.39 \pm 0.39$ & & \\
\hline \multicolumn{5}{|l|}{ Location } \\
\hline Upper & 13 & $5.13 \pm 1.26$ & 0.197 & 0.822 \\
\hline Middle & 14 & $5.44 \pm 1.27$ & & \\
\hline Lower & 25 & $5.29 \pm 1.26$ & & \\
\hline \multicolumn{5}{|l|}{ Depth invasion } \\
\hline $\mathrm{T} 1-\mathrm{T} 2$ & 20 & $4.99 \pm 0.85$ & & \\
\hline $\mathrm{T} 3-\mathrm{T} 4$ & 32 & $5.30 \pm 140$ & 0.519 & 0.598 \\
\hline \multicolumn{5}{|l|}{ CEA } \\
\hline$(+)$ & 6 & $6.35 \pm 1.71$ & & \\
\hline$(-)$ & 43 & $5.92 \pm 1.36$ & 0.595 & 0.574 \\
\hline \multicolumn{5}{|l|}{ CA19-9 } \\
\hline$(+)$ & 8 & $6.50 \pm 0.84$ & & \\
\hline$(-)$ & 42 & $5.87 \pm 1.46$ & 1.701 & 0.108 \\
\hline
\end{tabular}

\subsection{Expression of SDF-1 Protein by INH}

The difference between positive rate of SDF-1 protein in gastric cancer and corresponding non-cancerous gastric tissues, $94.2 \%$ (49/52) and 5.8\% (3/52), was significant in statistics $(\mathrm{P}<0.01)$ (see Figure 2 and Figure 3 ).

\section{Discussion}

SDF-1 was first discovered by Tashiro in cytokines secreted by mouse bone marrow stromal cells of the P6 line and its cDNA was isolated by expression cloning [9]. The gene is located on the long arm of chromosome 10. The SDF-1 cDNA is 1776 bp in length and the SDF-1 gene sequence is highly conserved. It has 7 transmembrane alpha helices and belongs to the CXC family of chemokines. The encoded receptor is CXCR4, coupling with G protein. Foreign scholars [10] first discovered that they were highly expressed in ovarian cancer cells, and later found in the study of breast cancer [2], prostate cancer [3], cervical 


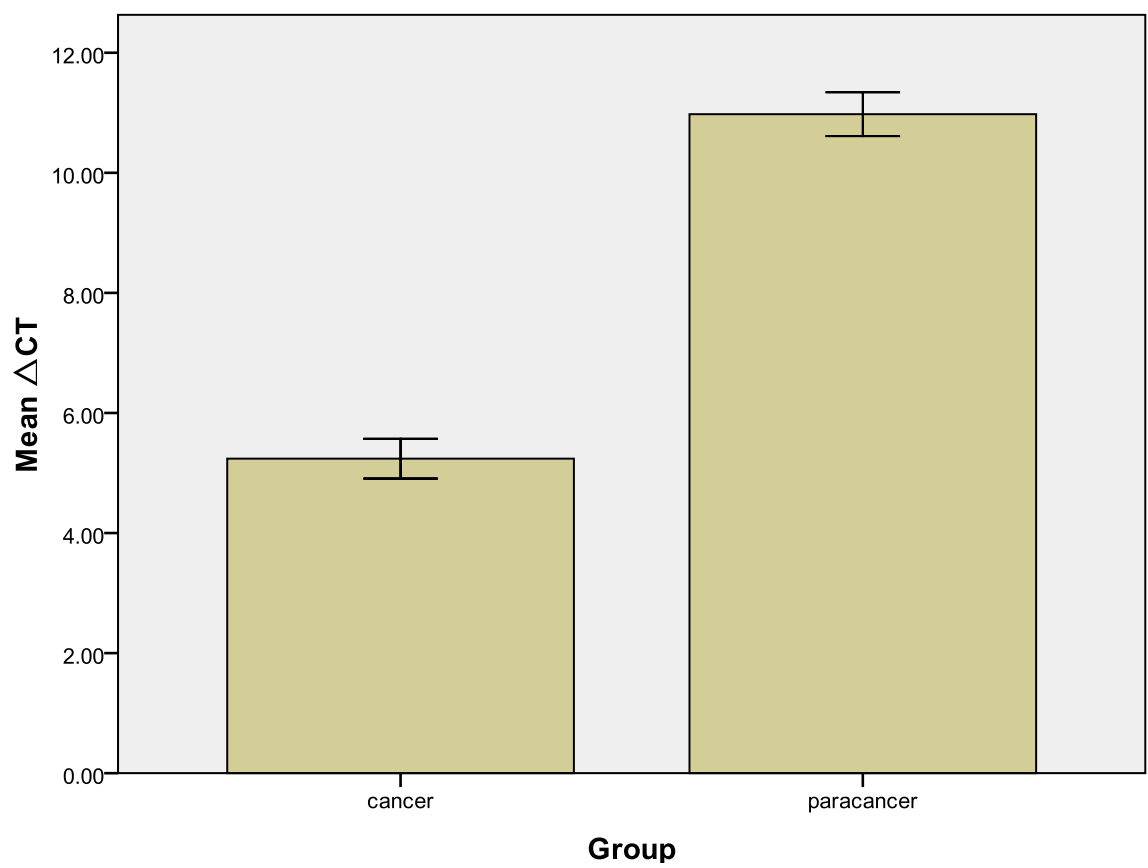

Figure 1. The mean $\triangle \mathrm{CT}$ value of SDF-1 in gastric cancer and corresponding non-cancerous gastric tissues.

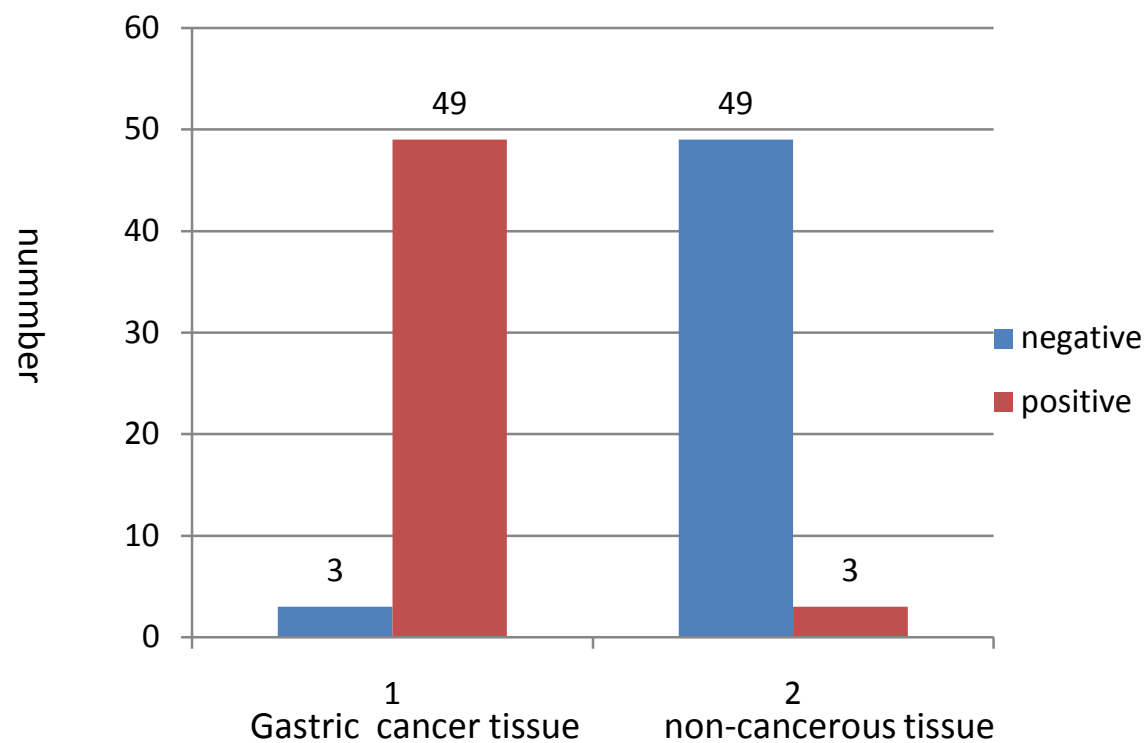

Figure 2. The expression of SDF-1 protein in gastric cancer and corresponding noncancerous gastric tissues.

cancer [10], and lung cancer [11], SDF-1 expression and Tumor growth, proliferation, invasion and metastasis. SDF-1 is widely expressed in a variety of cells and tissues, including immune cells, brain, heart, kidney, liver, lungs, and spleen. It plays a crucial role in the development of the immune system, circulatory system, and central nervous system [12]. SDF-1 regulates a variety of physiological and pathological processes, including cardiac and neuronal development, angiogenesis, stem cell migration, neovascularization, apoptosis, and tumorigenesis. 


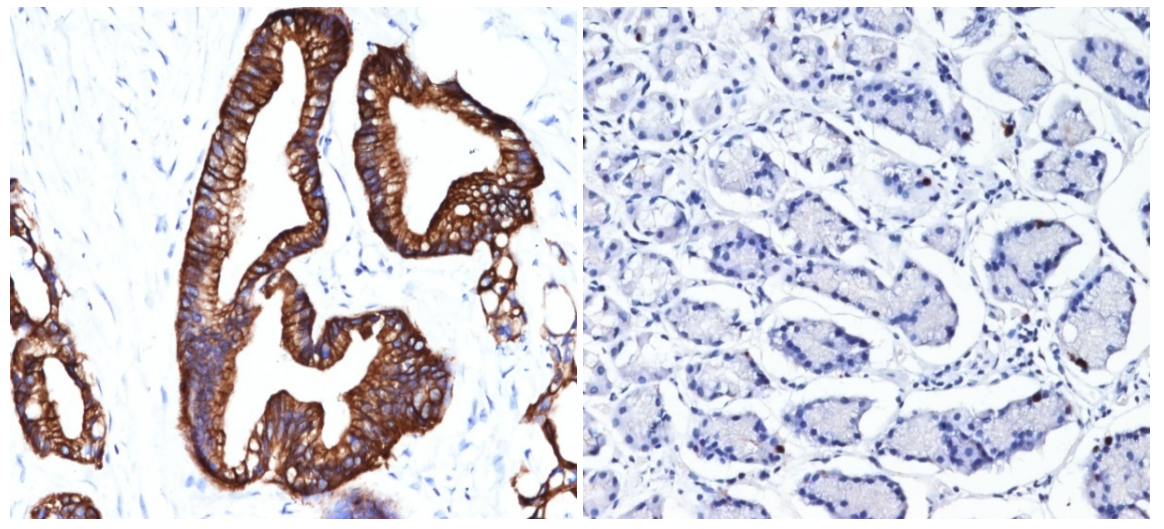

(a) (b)

Figure 3. SDF-1 protein expression in gastric cancer tissues (positive) (a) and corresponding non-cancerous gastric tissues (negative) (b) (both magnification 200×).

The structure and interaction mechanism of SDF-1 and its receptor CXCR4 are the basis for exerting its pathological and physiological functions. Studies [12] have found that overexpression of SDF-1 induces dysplasia of gastric mucosa by amplifying progenitor cells of interstitial myofibroblasts and epithelial cells. The expression of SDF-1 in gastric mucosa was gradually increased from adjacent gastric cancer to gastric precancerous lesions $\rightarrow$ early gastric cancer $\rightarrow$ advanced gastric cancer. The expression of SDF-1 in gastric mucosa was gradually increased throughout the entire process of gastric carcinogenesis, during the occurrence and development of gastric cancer, playing an important role. If it can be found through the study of its relationship with some of the pathological features of gastric cancer, then preoperative gastroscopy biopsy will help the initial assessment of the tumor, guide clinical treatment, but similar studies in the country are rare about whether the expression of SDF-1 is related to the level of peripheral blood CEA and CA19-9 and the HP value in gastric cancer. There is no report at home and abroad. It is related to the pathological features of gastric cancer patients such as clinical stage, lymph node metastasis, and gender and age. At present, there are fewer domestic studies and it is worth our further in-depth research and discussion. In this study, RT-PCR and immunohistochemical methods were used to detect the expression of SDF-1 in gastric cancer and adjacent normal tissues from the two levels of gene and protein, and the clinical data and tumor pathological characteristics were compared and analyzed, with a view to exploring the above issues.

The results of this study showed that the expression of SDF-1 in gastric cancer tissues was higher than that in adjacent normal tissues regardless of gene or protein level, thus confirming that it was an oncogene [2] [3] [9] [10] [11]. It has been found through research that it is not related to the lymph node metastasis of tumors, which is consistent with the results of Iwasa [4], but is inconsistent with the results of recent study by Ishigami et al. [13]. The study found that the expression of SDF-1 gene in intestinal type gastric cancer with lymph node metastasis was significantly higher than that in intestinal type gastric cancer with- 
out lymph node metastasis. The reason for the disagreement may be that the amount of specimens in this study is not large. However, whether there is a correlation between the two needs further research to confirm. The results of this study confirmed that SDF-1 gene and HP infection were not necessarily related to the occurrence and development of gastric cancer. Shibata [14] found that when SDF-1 transgenic mice were crossed with a mouse infected with Helicobacter pylori, they were found to cause gastric cancer. There is a synergistic effect on the effect. It is not related to tumor invasion depth and stage, which are inconsistent with the conclusion of Ishigami [13]. The results of this group also suggested that the SDF-1 gene expression had nothing to do with pathological features such as tumor location, differentiation, and other pathological features. In addition, this study also found that the expression of SDF-1 gene in gastric cancer patients was not related to gender and age, suggesting that there was no gender difference in SDF-1 gene expression, nor did it increase or decrease with age. The CEA and CA19-9 values can be used to evaluate the prognosis of gastric cancer patients [15] [16], whereas the expression of SDF-1 gene in gastric cancer tissues is not related to the level of preoperative peripheral blood CEA and CA19-9, so it is speculated that it cannot be used as an indicator of prognosis. The study showed that SDF-1 might play a significant role in the process of formation and development of gastric cancer as an oncogene, but cannot be used as an index to judge prognosis and predict recurrence. There is no definite conclusion about the mechanism of SDF-1 gene in the process of gastric carcinogenesis and development. It needs to be further studied.

\section{Conflicts of Interest}

The authors declare no conflicts of interest regarding the publication of this paper.

\section{References}

[1] Parkin, D.M., Bray, F., Ferlay, J., et al. (2005) Global Cancer Statistics, 2002. CA: $A$ Cancer Journal for Clinicians, 55, 74-108. https://doi.org/10.3322/canjclin.55.2.74

[2] Müller, A., Homey, B., Soto, H., et al. (2001) Involvement of Chemokine Receptors in Breast Cancer Metastasis. Nature, 410, 50-56. https://doi.org/10.1038/35065016

[3] Sun, Y.X., Fang, M., Wang, J., et al. (2007) Expression and Activation of Alpha v Beta 3 Integrins by SDF-1/CXC12 Increases the Aggressiveness of Prostate Cancer Cells. Prostate, 67, 61-73. https://doi.org/10.1002/pros.20500

[4] Iwasa, S., Yanagawa, T., Fan, J., et al. (2009) Expression of CXCR4 and Its Ligand SDF-1 in Intestinal-Type Gastric Cancer Is Associated with Lymph Node and Live Metastasis. Anticancer Research, 29, 4751-4758.

[5] NCCN Clinical Practice Guidelines in Oncology Gastric Cancer (Including Cancer in the Proximal $5 \mathrm{~cm}$ of the Stomach) [EB/OL]. NCCN Guidelines.

[6] Iwasa, S., Okada, K., Chen, W.T., et al. (2005) Increased Expression of Seprase, a Membrane-Type Serine Protease, Is Associated with Lymph Node Metastasis in Human Colorectal Cancer. Cancer Letters, 227, 229-236.

https://doi.org/10.1016/j.canlet.2004.06.030 
[7] Wu, J.P., Qiu, F.Z., Wu, M.C., et al. (2008) Huang Jia Si Surgery. 7th Edition, People's Health Publishing House, Beijing, 1450.

[8] Che, X.B. and Liu, W.Z. (2002) Evaluation of Common Diagnostic Methods for Helicobacterpylori. Chinese Journal of Digestion, 22, 691-693.

[9] Zou, W., Machelon, V., Coulomb-L'Hermin, A., et al. (2001) Stromal-Derived Factor-1 in Human Tumors Recruits and Alters the Function of Plasma Cytoid Precursor Dendritic Cells. Nature Medicine, 7, 1339-1346.

[10] Shen, X.Y, Wang, S.H, Liang, M.L., et al. (2008) The Role and Mechanism of CXCR4 and Its Ligand SDF-1 in Cervical Cancer Metastasis. Cancer, 27, 1044-1049.

[11] Wagner, P.L., Hyjek, E., Vazquez, M.F., et al. (2009) CXCL 12 and CXCR4 in Adenocarcinoma of the Lung: Association with Metastasis and Survival. The Journal of Thoracic and Cardiovascular Surgery, 137, 615-621. https://doi.org/10.1016/j.jtcvs.2008.07.039

[12] Bleul, C.C., Fuhlbrigge, R.C., Casasnovas, J.M., et al. (1996) A Highly Efficacious Lymphocyte Chemoattractant, Stromal Cell-Derived Factor-1(SDF-1). Journal of Experimental Medicine, 184, 1101-1109. https://doi.org/10.1084/jem.184.3.1101

[13] Ishigami, S., Natsugoe, S., Okumura, H., et al. (2007) Clinical Implication of CXCL12 in Gastric Cancer. Annals of Surgical Oncology, 14, 3154-3158. https://doi.org/10.1245/s10434-007-9521-6

[14] Shibata, W., Ariyama, H., Westphalen, C.B., et al. (2013) Stromal Cell-Derived Factor-1 over Expression Induces Gastric Dysplasia through Expansion of Stromal Myofibroblasts and Epithelial Progenitors. Gut, 62, 192-200. https://doi.org/10.1136/gutjnl-2011-301824

[15] Zhang, Y.L., Xue, Y.W., Lan, X.W., et al. (2010) Research on the Prognostic Value of Tumor Markers CA19-9 and CEA in Gastric Cancer Metastasis and Prognosis. Journal of Harbin Medical University, 44, 181-184, 188.

[16] Ucar, E., Semerci, E., Ustun, H., et al. (2008) Prognostic Value of Preoperative CEA, CA19-9, CA72-4, and AFP Levels in Gastric Cancer. Advances in Therapy, 25, 1075-1084. https://doi.org/10.1007/s12325-008-0100-4 